\title{
Correction to: One-step synthesis of versatile magnetic nanoparticles for efficiently removing emulsified oil droplets and cationic and anionic heavy metal ions from the aqueous environment
}

\section{Ting Lü ${ }^{1}$ • Dongming $\mathrm{Qi}^{2} \cdot$ Dong Zhang ${ }^{1} \cdot$ Chuan Zhang ${ }^{1} \cdot$ Hongting Zhao ${ }^{1}$}

Published online: 25 June 2019

(C) Springer-Verlag GmbH Germany, part of Springer Nature 2019

\section{Correction to: Environmental Science and Pollution Research (2019) 26:6153-6166 \\ https://doi.org/10.1007/s11356-018-4002-y}

On page 6156, "Regeneration of the MNPs for $\mathrm{Cu}$ (II) and $\mathrm{Cr}(\mathrm{VI})$ adsorption was conducted by using $0.1 \mathrm{~mol} / \mathrm{L} \mathrm{HCl}$ solution and $\mathrm{NaOH}$ solution as eluents, respectively" should read "Regeneration of the MNPs for $\mathrm{Cu}(\mathrm{II})$ and $\mathrm{Cr}(\mathrm{VI})$ adsorption was conducted by using $\mathbf{1 . 0} \mathbf{~ m o l} / \mathbf{L ~} \mathrm{HCl}$ solution and $\mathrm{NaOH}$ solution as eluents, respectively".

The authors also regret to inform that we have put a wrong XRD curve (for the sample prepared at $12 \mathrm{~h}$ ) in previous Fig. 2, and hence the corrected Fig. 2 should be as follow:

These corrections do not change the discussion or conclusion of the article. We regretfully apologize for any inconvenience caused.

Publisher's note Springer Nature remains neutral with regard to jurisdictional claims in published maps and institutional affiliations.

The online version of the original article can be found at https://oi.org/ 10.1007/s11356-018-4002-y

Hongting Zhao

info-iem@hdu.edu.cn

Institute of Environmental Materials and Applications, College of Materials and Environmental Engineering, Hangzhou Dianzi University, Hangzhou 310018, China

2 Key Laboratory of Advanced Textile Materials and Manufacturing Technology, Ministry of Education, Zhejiang Sci-Tech University, Hangzhou 310018, China

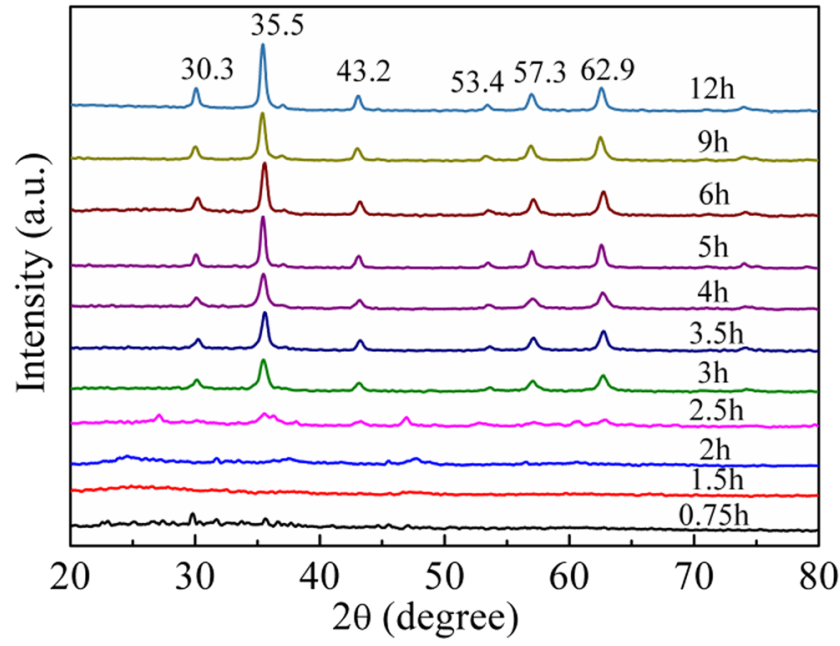

Fig. 2 XRD patterns of the product prepared via solvothermal method after different reaction times 